\title{
Evapotranspiration simulated by CRITERIA and AquaCrop models in stony soils
}

\author{
Pasquale Campi, ${ }^{1}$ Francesca Modugno, ${ }^{1}$ Alejandra Navarro, ${ }^{1}$ Fausto Tomei, ${ }^{2}$ Giulia Villani, ${ }^{2,3}$ \\ Marcello Mastrorilli ${ }^{1}$ \\ ${ }^{1}$ Unità di Ricerca per i Sistemi Colturali degli Ambienti Caldo-Aridi, Consiglio per la Ricerca \\ in Agricoltura e l'Analisi dell'Economia Agraria, Bari; ${ }^{2}$ ARPA Emilia-Romagna, Servizio \\ Idro-Meteo-Clima, Bologna; ${ }^{3}$ Dipartimento di Scienze e Tecnologie Agro-Alimentari, \\ Università di Bologna, Italy
}

\begin{abstract}
The performance of a water balance model is also based on the ability to correctly perform simulations in heterogeneous soils. The objective of this paper is to test CRITERIA and AquaCrop models in order to evaluate their suitability in estimating evapotranspiration at the field scale in two types of soil in the Mediterranean region: non-stony and stony soil. The first step of the work was to calibrate both models under the non-stony conditions. The models were calibrated by using observations on wheat crop (leaf area index or canopy cover, and phenological stages as a function of degree days) and pedo-climatic measurements. The second step consisted in the analysing the impact of the soil type on the models performances by comparing simulated and measured values. The outputs retained in the analysis were soil water content (at the daily scale) and crop evapotranspiration (at two time scales: daily and crop season). The model performances were evaluated through four statistical tests: normalised difference (D\%) at the
\end{abstract}

Correspondence: Pasquale Campi, Unità di Ricerca per i Sistemi Colturali degli Ambienti Caldo-Aridi (CRA-SCA), Consiglio per la Ricerca in Agricoltura e l'Analisi dell'Economia Agraria, via Celso Ulpiani 5, 70125 Bari, Italy. Tel. +39.080 .5475014 - Fax: +39.080 .5475023 .

E-mail: pasquale.campi@entecra.it

Key words: Soil skeleton; soil water balance; daily evapotranspiration; soil water content; durum wheat.

Acknowledgements: this work was carried out within the project Scenarios of adaptation of the Italian agriculture to the climatic changes (AGROSCENARI), contract no. D.M. 8608/7303/2008 of the Italian Ministry of the Agricultural and Forestry Politics.

Conference presentation: SIA XLIII Congress, Pisa, 2014.

Received for publication: 30 January 2015 .

Revision received: 8 April 2015.

Accepted for publication: 11 April 2015.

(C) Copyright P. Campi et al., 2015

Licensee PAGEPress, Italy

Italian Journal of Agronomy 2015; 10:658

doi:10.4081/ija.2015.658

This article is distributed under the terms of the Creative Commons Attribution Noncommercial License (by-nc 3.0) which permits any noncommercial use, distribution, and reproduction in any medium, provided the original author(s) and source are credited. seasonal time scale; and relative root mean square error (RRMSE), efficiency index (EF), coefficient of determination $\left(\mathrm{r}^{2}\right)$ at the daily scale. At the seasonal scale, values of $\mathrm{D} \%$ were less than $15 \%$ in stony and on-stony soils, indicating a good performance attained by both models. At the daily scale, the RRMSE values $(<30 \%)$ indicate that the evapotranspiration simulated by CRITERIA is acceptable in both soil types. In the stony soil conditions, 3 out 4 statistical tests (RRMSE, EF, $\mathrm{r}^{2}$ ) indicate the inadequacy of AquaCrop to simulate correctly daily evapotranspiration. The higher performance of CRITERIA model to simulate daily evapotranspiration in stony soils, is due to the soil submodel, which requires the percentage skeleton as an input, while AquaCrop model takes into account the presence of skeleton by reducing the soil volume.

\section{Introduction}

The karstic nature of many soils in the Mediterranean region, did not limit the diffusion of several crops. Even in marginal soils, such as the alfi-soils rich in stones, high quality productions are feasible, if irrigation is supplied. Is it the case of the cropping systems in many areas of Southern Italy where, calcareous fragments are present along the whole soil profile deriving by the continuous breaking and grinding of the superficial rocks. The benefits of grinding calcareous rocks are two-fold: i) increase rooting zone; and ii) release of available calcium (Coppola et al., 2013).

In some case the presence of stones into the soil profile should be interpreted as an agronomic benefit. Rock fragments reduce the water flow (Mehuys et al., 1975; Childs and Flint, 1990) or create new fissures at the rock - fine earth interfaces (Fies et al., 2002; Tokunaga et al., 2003) or increase the water retention capacity of soil (Hanson and Blevins, 1979; Brouwer and Anderson, 2000; Cousin et al., 2003). Therefore, stony soils have hydraulic properties that are highly different from those of non-stony soils (Mehuys et al., 1975; Sharma et al., 1993; Fies et al., 2002).

In these soils, measuring soil water content is a complex task. In the case of the thermo-gravimetric technique for measuring the soil water content, the weight of the soil samples does not consider the stones (Campi et al., 2010). As a consequence, the available water in the soil volume (calculated multiplying the volumetric soil water content by the soil depth) results underestimated if an adjusting parameter is not considered for taking into account the space of the stones.

The question is especially important for in situ measurements of soil water content by time-domain reflectometery or capacitive sensors. In the stony soils, the probes allow measuring actual soil moisture, however it is not representative of the soil water held in each layer of the soil profile. So for a correct water balance, the soil water 
content should be decreased by the volume of stones (Ravina and Magier, 1984; Hendrickx et al., 1991; Dann et al., 2009, Campi et al., 2010).

In such conditions, evapotranspiration can be estimated by the water balance calculated from measurements of soil water content and the apparent depth of the soil corresponding to a lower value than the actual soil profile explored by the root system (more the stone volume, smaller the apparent depth).

Several models are available for calculating soil water content along the whole soil profile (Gerke and van Genuchten, 1993; Jarvis, 1994; van Dam, 2000; Vogel et al., 2000; Coppola et al., 2012), however their performance in simulating the water balance should be evaluated also in stony soils. Finally the presence of skeleton in the soils should be taken into account (Ravina and Magier, 1984; Brakensiek and Rawls, 1994; Poesen and Lavee, 1994; Cerda, 2001; Fies et al., 2002; Cousin et al., 2003; Baetens et al., 2009; Novak et al., 2011) in any model simulating the soil water changes during the crop cycles.

In this paper, the performances of two operative models, CRITERIA and AquaCrop, are evaluated in non-stony soil and in stony soils. The final aim is to test the hypothesis that the CRITERIA and AquaCrop model can be used as a tool for estimating the crop evapotranspiration.

\section{Materials and methods}

\section{Models}

CRITERIA (Marletto and Zinoni, 1998; Marletto et al., 2007) is a modeling system for the simulation of soil water balance developed at ARPA-SIMC that can be used also at the regional scale. The system, provided with daily data of precipitation and temperature, estimates the evapotranspiration and calculates the daily flow of superficial runoff, hypodermic runoff and drainage.

For calculating the soil water content the CRITERIA model requires as input granulometric (fine soil and skeleton) and hydrological (curve tensiometric and infiltration rate) parameters. Some of these variables are easy to measure; others are estimated through algorithms based on meteorological data and characteristics of soil and crops. The water balance is calculated on a daily basis.

AquaCrop model (Steduto et al., 2009) is a crop water productivity simulation model, resulting from the revision of the Food and Drug Administration (FA0) Irrigation and Drainage Paper No. 33 by Doorenbos and Kassam (1979). Similarly to other crop-growth models, AquaCrop further develops a structure (sub-model components) that includes: the soil, with its water balance; the crop, with its development, growth and yield; the atmosphere, with its thermal regime, rainfall, evaporative demand and carbon dioxide concentration $\left(\mathrm{CO}_{2}\right)$; and the management, with its major agronomic practices, such as irrigation and fertilisation.

For calculating the soil water content, the AquaCrop model requires only hydrological parameters (saturation, field capacity, wilting point and infiltration rate). Simulation runs of AquaCrop are executed with a daily time step, using either calendar days or degree days.

\section{Sites and climate}

Two experimental dataset were utilised to validate the CRITERIA and AquaCrop model at two sites in Southern Italy: Rutigliano (lat.: $40^{\circ} 59^{\prime}$ $\mathrm{N}$, long.: $17^{\circ} 01^{\prime} \mathrm{E}$, alt.: $147 \mathrm{~m}$ asl), and Foggia (lat.: $41^{\circ} 26^{\prime} \mathrm{N}$, long.: $15^{\circ}$ $30^{\prime}$ E, alt.: $90 \mathrm{~m}$ asl), on the experimental farms of the Agricultural Research Council - Research Unit for Cropping Systems in Dry Environments (CRA - SCA). The studies were focused on durum wheat (cv Simeto) grown during 2013 season.
Southern Italy boosts to a Mediterranean climate characterised by warm and dry summers, with a maximum air temperature sometimes above $40^{\circ} \mathrm{C}$ and a minimum relative humidity often below $20 \%$ (Campi et al., 2009). The annual rainfall is almost the same at both sites, 535

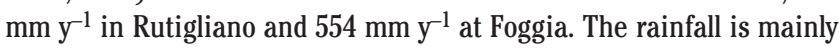
concentrated in the autumn and late winter and it is greatly reduced or absent in the spring-summer period. The soil at the Rutigliano site is mainly clayey where stones represent the $10 \%$ of the soil volume in the top soil layer $(0-0.6 \mathrm{~m})$ and $65 \%$ of the soil volume below the first soil layer (Modugno, 2008). The soil of Foggia has a 3 m-depth and a loamclay texture. Nonetheless, a $1.2 \mathrm{~m}$-deep calcareous layer prevents the roots from expanding beyond this layer (Table 1).

\section{Crop management and growth analysis}

Durum wheat (cv Simeto) was sown on $7^{\text {th }}$ December 2012 at Foggia site and on $4^{\text {th }}$ December 2012 at Rutigliano site on 1 ha fields. The durum wheat crops were grown using conventional agro-techniques $\left(120 \mathrm{~kg}_{2} \mathrm{O}_{5}\right.$ $\mathrm{ha}^{-1}$ before sowing and $100 \mathrm{~kg} \mathrm{ha}^{-1}$ of N, 90 days after sowing).

Both wheat fields were divided in 4 blocks where the parameters for the model calibration were measured (in 4 replications).

The field measurements were: i) dates of the main phenological stages [used for the CRITERIA and AquaCrop calibration to calculate growing degree days (GDD)]; ii) leaf area index (LAI) measured at the main phenological stages, with an area meter (LAI-2000 Plant Canopy Analyzer; LI-COR, Lincoln, NE, USA); iii) evapotranspiration, as described in the following sub-paragraph.

\section{Evapotranspiration measurements}

Evapotranspiration was estimated using a simplified soil water balance approach (Mastrorilli et al., 1998). At the Rutigliano site, runoff and capillary rise are negligible because of the flat ground and the presence of rocky layer that limits the ascending water.

At the Foggia sites, runoff can be omitted because the area is flat, while the capillary rise can be assumed to be zero because of the presence of a calcareous layer at $1.2 \mathrm{~m}$ deep that prevents the roots from expanding and the water stored in the deeper soil layers from moving up to the soil surface.

The simplified equation for the soil water balance can be expressed as:

$$
\mathrm{ET}= \pm \Delta \mathrm{W}+\mathrm{P}-\mathrm{Dr}
$$

where: ET, crop evapotranspiration (mm); P, precipitation or/and irrigation $(\mathrm{mm}) ; \pm \Delta \mathrm{W}$, the difference in soil water content.

The same technique for monitoring the soil water status was used for both sites.

In case of Rutigliano site, the water content in presence of stone

Table 1. The main soil characteristics observed at the experimental sites.

\begin{tabular}{lcc}
\hline Soil characteristics & Rutigliano & Foggia \\
Stone (\%) & 10 & 0 \\
Clay (\%) & 55 & 35 \\
\hline Silt (\%) & 30 & 40 \\
Sand (\%) & 15 & 25 \\
\hline Water content at field saturation (\% in volume) & 48 & 50 \\
Water content at field capacity (\% in volume) & 34 & 39 \\
\hline Water content at wilting point (\% in volume) & 22 & 20 \\
\hline
\end{tabular}


$\left(\mathrm{W}_{\mathrm{st}}\right)$ was calculated according the equation 2 (Ravina and Magier, 1984; Hendrickx et al., 1991; Dann et al., 2009; Campi et al., 2010):

$$
\mathrm{W}_{\mathrm{st}}=\mathrm{W}\left(1-\mathrm{V}_{\mathrm{st}}\right)
$$

where the $V_{\text {st }}$ is the volume of stones.

Capacitive probes of $0.1 \mathrm{~m}$ in length (10HS; Decagon Devices, Inc., Pullman, WA, USA) were installed horizontally into the soil at two layers $(-15$ and $-45 \mathrm{~cm}$ from the soil surface at Rutigliano site and -20 and $-60 \mathrm{~cm}$ at Foggia site). The probes were linked to Grillo datalogger [Tecno.EL srl, Formello (RM), Italy].

The drainage (Dr) was estimated as the amount of water exceeding the maximum water capacity in the whole soil profile.

This approach to estimate ET was validated in diverse soil water conditions by comparing the ET estimated by the simplified soil water balance equation and ET measured by the Bowen ratio method (Rana and Katerji, 1998) at the Rutigliano site on a daily scale. Differences within $10 \%$ were observed between the daily ET measured by the two methods (Mastrorilli et al., 1998).

Soil water content data measured using the capacitive probes were only available 24 and 58 days after sowing at Rutigliano and Foggia sites, respectively. In this period, the cumulative evapotranspiration was calculated according to Eq. (1). In particular, $\Delta \mathrm{W}$ is the difference between the values of the soil water content measured by the thermogravimetric method at sowing and at the first day when the data from capacitive system became available.

\section{Model calibrations}

For model calibration the Foggia dataset was used.

\section{Input to AquaCrop}

The application of the AquaCrop model to a given crop requires that a series of inputs is determined. The inputs are related to: i) climate; ii) crop; and iii) soil properties.

i) Climate inputs concern the daily reference evapotranspiration, calculated in according to the FA0-56 methodology (Allen et al., 1998). All the climatic parameters have been collected from standard agrometeorological stations, close to the experimental plots in Rutigliano and in Foggia.

ii) The crop development is expressed as GDD at each phenological stage (Table 2).

The canopy ground cover (CC) can be derived using the Ritchie model (Belmans et al., 1983; Ritchie et al., 1985) from the following equation:

$$
\mathrm{CC}=1-\exp (-\mathrm{K} \mathrm{LAI})
$$

where LAI is the measured leaf area index and $\mathrm{K}$ is the extinction coefficient, which was assumed to be 0.65 for wheat (Heng et al., 2009).

The values of CC calculated by the AquaCrop model and those calculated by Eq. (3) are reported in Figure 1. The simulated and observed $\mathrm{CC}$ values show a good agreement. As for the root depth, a value of 1.2 $\mathrm{m}$ was used.

iii) Soil inputs concern three parameters previously reported in Table 3 (wilting point, field capacity, soil depth).

\section{Input to CRITERIA}

The calibration of the CRITERIA model was done taking into account the following measurements:

- Agrometeorological data: daily measurements of global radiation, wind speed, air humidity and temperature, collected from standard agro-meteorological stations close to the experimental plots in
Rutigliano and Foggia.

- LAI measures compared with simulated values by CRITERIA (Figure 1).

- GDD for the main phenological stages were determined by observing the date when $50 \%$ of the plants reach a phenological stage (Table 3).

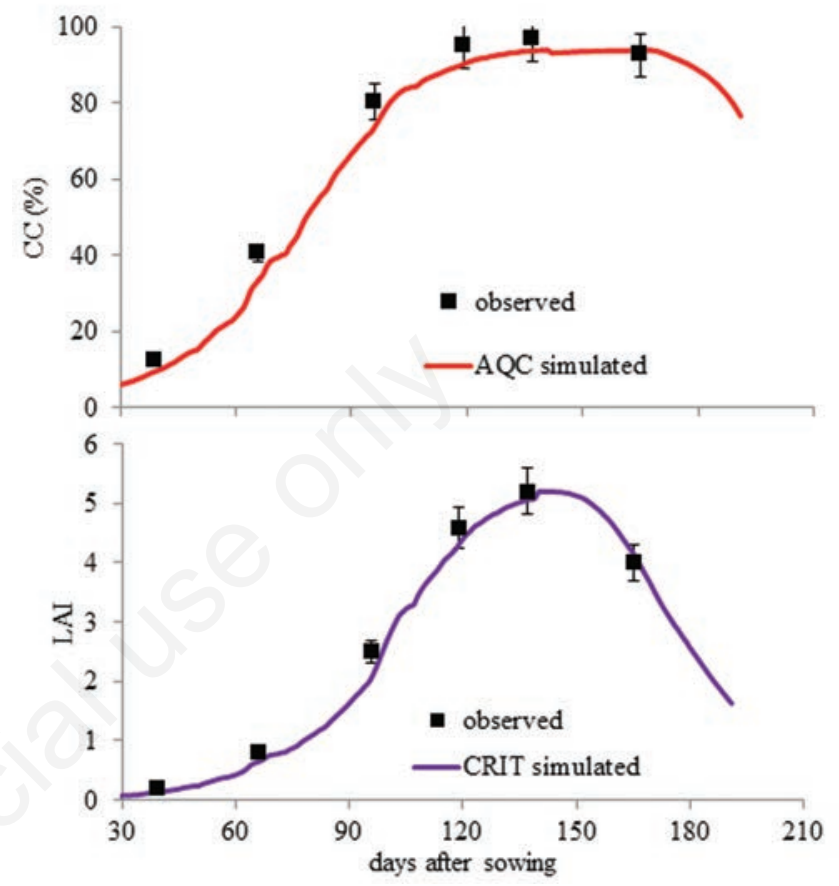

Figure 1. Observed and simulated values of canopy ground cover (CC) and leaf area index (LAI) used in models' calibration. AQC, AquaCrop model; CRIT, CRITERIA model.

Table 2. Comparison between the default values contained in the AquaCrop library (Raes et al., 2009) and the calibrated values.

\begin{tabular}{lccc} 
Parameter description & Default & Calibr. & Unit \\
Plants per hectare & 450,000 & 260,000 & $\mathrm{n}$. \\
Maximum canopy cover (CCX) & 96 & 96 & $\%$ \\
\hline GDD from sowing to emergence & 150 & 114 & ${ }^{\circ} \mathrm{C}$ \\
GDD from sowing to maximum rooting depth & 1186 & 1083 & ${ }^{\circ} \mathrm{C}$ \\
\hline GDD from sowing to start senescence & 1700 & 1710 & ${ }^{\circ} \mathrm{C}$ \\
GDD for sowing to maturity & 2400 & 2204 & ${ }^{\circ} \mathrm{C}$ \\
\hline GDD for swing to flowering & 1250 & 1140 & ${ }^{\circ} \mathrm{C}$ \\
GDD of length of flowering stage & 200 & 171 & ${ }^{\circ} \mathrm{C}$ \\
\hline
\end{tabular}

GDD, growing degree days.

Table 3. Growing degree days for principal phenological stages used for CRITERIA calibration.

\begin{tabular}{lcc} 
Parameter description & Parameter value & Unit \\
GDD from sowing to emergence & 114 & ${ }^{\circ} \mathrm{C}$ \\
GDD from sowing to maximum LAI & 1083 & ${ }^{\circ} \mathrm{C}$ \\
\hline GDD from sowing to start senescence & 1710 & ${ }^{\circ} \mathrm{C}$ \\
\hline
\end{tabular}

GDD, growing degree days; LAI, leaf area index. 
- Root depth: a value of $1.2 \mathrm{~m}$ was used.

- Physical and hydrological characteristics of soil (Table 1). In this case $10 \%$ of skeleton in the top soil layer $(0-0.6 \mathrm{~m})$ and $65 \%$ of skeleton below the first soil layer were considered.

\section{Model validation}

The performance of each model was evaluated through 4 statistical tests:

i) normalised difference (D, in \%) is the difference between the simulations and measured values, divided by the measurements. If the values of D did not exceed 15\%, as suggested by Brisson et al. (2002), the simulation could be retained as acceptable because the differences fall within the error range that is generally admitted for field crop researches;

ii) modelling efficiency index (Nash and Sutcliffe, 1970), as calculated by the following equation:

$$
E F=1-\frac{\sum_{i=1}^{n}\left(\text { Predicted }_{i}-\text { Observed }_{i}\right)^{2}}{\sum_{i=1}^{n}\left(\text { Observed }_{i}-\text { AvgObserved }^{2}\right.}
$$

where $n$ represents the number of data pairs, $i$ is the pair index and AvgObserved is the average of the observed data.

EF provides a simple index of model performance on a relative scale, where $\mathrm{EF}=1$ indicates a perfect fit, $\mathrm{EF}=0$ suggests that the model predictions are no better than the average, and a negative value indicates poor model performance;

iii) the relative root mean square error (RRMSE), calculated from the following equation:

$$
\text { RRMSE }=\sqrt{\frac{\sum_{i=1}^{n}\left(P_{i}-O_{i}\right)^{2}}{n}} \cdot \frac{100}{\overline{\mathrm{O}}}
$$

where $n$ is the number of observations, $P_{i}$ is the value predicted by models,
$\bar{O}_{i}$ is the measured value, and is the mean of the measured values.

The validation is considered to be excellent when the RRMSE is $<10 \%$, good if the RRMSE is between 10 and 20\%, acceptable if the RRMSE is between 20 and 30\%, and poor if $>30 \%$ (Jamieson et al., 1991);

iv) the coefficient of determination $\left(\mathrm{r}^{2}\right)$ is defined as the squared value of the Pearson correlation coefficient; it signifies the proportion of the variance in measured data explained by the model. It ranges from 0 to 1 , with values close to 1 indicating a good agreement, and typically values greater than 0.5 are considered acceptable in watershed simulations (Moriasi et al., 2007).

\section{Results and discussion}

Figure 2 shows the daily variation in soil water content for each site during the crop season monitored by the capacitive sensors. The differences in soil water content between Foggia and Rutigliano sites are due to amount of rainfall and to the soil characteristic (mainly the soil depth and the soil water availability, i.e., the difference between field capacity and wilting point).

Although rainfall was different in the two sites (325 mm in Foggia and $190 \mathrm{~mm}$ in Rutigliano), they determined a soil water content close to field capacity in the period from January to March 2013. However the amount of water stored in the soil profile changes in the two sites: the absence of the skeleton in the soil (Foggia site) determines a soil water content at the field capacity $(450 \mathrm{~mm})$ greater than stony soil at Rutigliano (290 mm), where the presence of skeleton reduces the soil water reservoir in the layer explored by the roots.

The values of the statistical tests listed in Table 4 show that both models simulate adequately the soil water content in both types of soil at a daily scale. In particular RRMSE is less than 10\% (excellent performance), $\mathrm{EF}$ and $\mathrm{r}^{2}$ is close to 1. Only in the case of the simulations carried out by AquaCrop model on the site of Rutigliano, EF has lower values $(\mathrm{EF}=0.6)$. In fact, Figure 2 shows how the values of $\mathrm{W}$ simulated by AquaCrop were consistently lower than those measured by the capacitance probes or simulated by the CRITERIA model.

As for the evapotranspiration, Table 5 shows that the seasonal evapotranspiration $(\Sigma \mathrm{ET})$ of durum wheat grown in Foggia was higher by

Table 4. Relative root mean square error, efficiency index and coefficient of determination assesed on weat grown at two sites for daily-

\begin{tabular}{|c|c|c|c|c|c|c|c|}
\hline Models & Sites & & W & & & ETc & \\
\hline & & RRMSE (\%) & EF & $r^{2}$ & RRMSE (\%) & EF & $r^{2}$ \\
\hline AquaCrop & Foggia & 5 & 0.8 & 0.91 & 27 & 0.6 & 0.79 \\
\hline & Rutigliano & 6 & 0.6 & 0.96 & 31 & 0.4 & 0.66 \\
\hline CRITERIA & Foggia & 4 & 0.9 & 0.93 & 27 & 0.7 & 0.78 \\
\hline & Rutigliano & 3 & 0.9 & 0.98 & 24 & 0.8 & 0.80 \\
\hline
\end{tabular}
simulated values by AquaCrop and CRITERIA models of soil water content and crop evapotranspiration.

W, water content; ETc, crop evapotranspiration; RRMSE, relative root mean square error; EF, efficiency index; $\mathrm{r}^{2}$, coefficient of determination.

Table 5. Seasonal evapotranspiration, observed and simulated by AquaCrop and CRITERIA models for durum wheat crop grown at

\begin{tabular}{|c|c|c|c|c|c|}
\hline \multirow[t]{2}{*}{ Sites } & \multicolumn{3}{|c|}{$\Sigma \mathrm{ETc}(\mathrm{mm})$} & \multicolumn{2}{|c|}{ D (\%) } \\
\hline & Obs & $\mathrm{AQC}$ & CRIT & Obs us AQC & Obs us CRIT \\
\hline Foggia & 360 & 414 & 368 & 12.8 & -0.4 \\
\hline Rutigliano & 247 & 260 & 243 & 5.0 & -1.6 \\
\hline
\end{tabular}
two sites. The normalised differences between simulated and observed values are also reported.

ETc, seasonal evapotranspiration; D, differences; Obs, observed; AQC, AquaCrop model; CRIT, CRITERIA model. 
$32 \%$, compared to that grown in Rutigliano (360 vs $247 \mathrm{~mm}$ ). This is due to the lower water availability in the soil profile at Rutigliano.

The statistical test D\% (normalised difference) showed that CRITERIA and AquaCrop models have a good skill in simulating seasonal ET (no D value exceeds the 15\% threshold), both in non-stony (Foggia) and in stony soils (Rutigliano). The low vales of D (less than $2 \%$ in the CRITERIA model and $13 \%$ in AquaCrop) let to retain that they simulate $\Sigma$ ET adequately.

Figure 3 shows the observed and simulated values of the daily ET for two sites.

Statistical indicators (RRMSE, EF and $\mathrm{r}^{2}$ ) have been calculated for the periods when daily measurements of ET were available. These values show an acceptable skill of CRITERIA and AquaCrop models in simulating ET, at a daily scale in the case of the non-stony soil. At the Foggia site the statistics of the AquaCrop outputs were acceptable (RRMSE $<30 \%, \mathrm{EF}>0.6$ and $\mathrm{r}^{2}=0.8$ ). Whereas, in the case of the stony soil (Rutigliano site), the skill of the AquaCrop model decreases. In fact, RRMSE exceeds the $30 \%$ threshold (non acceptable simulation), and the EF and $\mathrm{r}^{2}$ values decrease ( 0.4 and 0.66 , respectively). CRITERIA performs adequately daily ET in stony and non-stony soil conditions. The better performance of CRITERIA model to simulate ET in stony soils is due to the sub-model component of soil that requires detailed input on the chemical (\% of active limestone, $\%$ of limestone total, \% of organic matter and cation exchange capacity in $\mathrm{cmol} \mathrm{kg}^{-1}$ ), and granulometric (percentage skeleton, sand, silt and clay) parameters. While the parameters required as input on the physical characteristics (coefficient of saturation, water content to saturation, field capacity and wilting point), are the same as those required by AquaCrop model.

However, AquaCrop model does not require any input regarding the granulometry of the soil. As a consequence, the only way to consider the presence of the skeleton is the introduction of restrictive soil layers, the apparent depth, which accounts for a less soil volume because of the presence of skeleton.

The presence of the restrictive soil layer determines an alteration of the soil water balance, since it is considered as an impermeable layer that modifies the drainage flow. In fact, Table 6 shows that the seasonal drainage simulated by AquaCrop model is underestimated respect to the data determined through the Equation 1. Statistics (D\% value) for drainage simulated by AquaCrop exceeds the 15\% threshold, while D values for CRITERIA outputs are lower than the 15\% threshold.

In particular, at Rutigliano site, during the observed period, rainfall
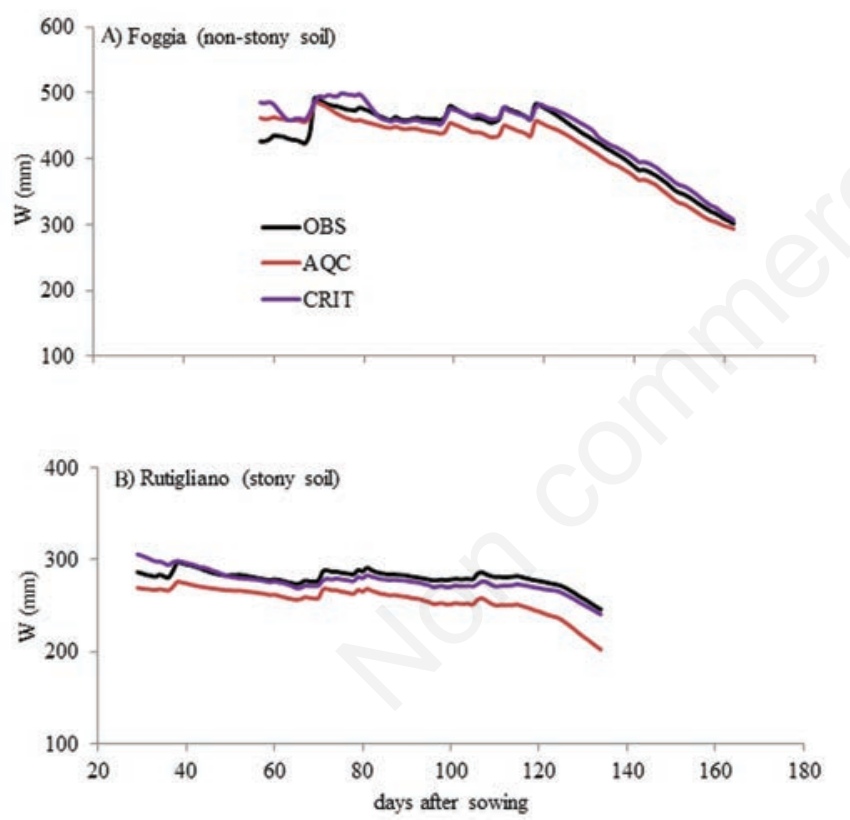

Figure 2. Values of soil water content $(\mathrm{W})$ measured and simulated by AquaCrop (AQC) and CRITERIA (CRIT) models during the wheat season at Foggia and Rutigliano. OBS, observed.

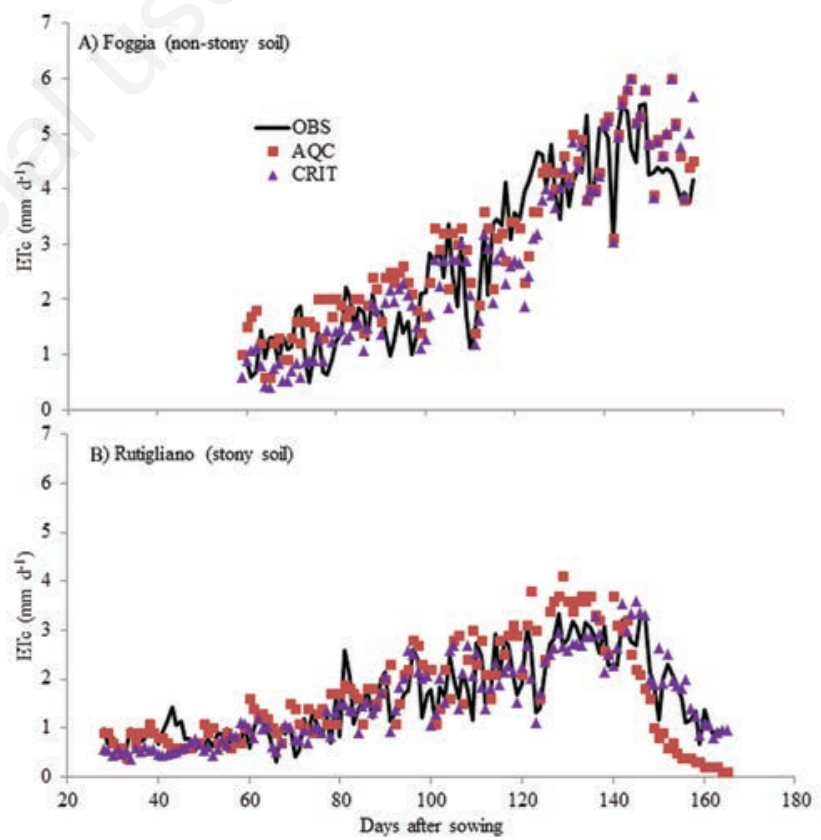

Figure 3. Daily values of wheat evapotranspiration (ETc) measured and simulated by AquaCrop (AQC) and CRITERIA (CRIT) models during the wheat season at Foggia and Rutigliano. OBS, observed.

Table 6. Seasonal drainage, observed and simulated by AquaCrop and CRITERIA models for durum wheat crop grown at two sites. The normalised differences between simulated and observed values are also reported.

\begin{tabular}{|c|c|c|c|c|c|}
\hline \multirow{2}{*}{ Sites } & \multicolumn{3}{|c|}{$\Sigma \mathrm{Dr}(\mathrm{mm})$} & \multicolumn{2}{|c|}{ D (\%) } \\
\hline & Obs & AQC & CRIT & Obs us AQC & Obs us CRIT \\
\hline Foggia & 60 & 35 & 69 & 41 & -15 \\
\hline Rutigliano & 29 & 3 & 34 & 93 & -14 \\
\hline
\end{tabular}

$\Sigma$ Dr, seasonal drainage; D, differences; Obs, observed; AQC, AquaCrop model; CRIT, CRITERIA model. 
was $190 \mathrm{~mm}$, and AquaCrop simulates only $3 \mathrm{~mm}$ of drainage that is a too value for the stony soils, which are characterised by high permeability (Giardini, 2002). Such evidence in part explains why the AquaCrop model overestimates $\Sigma$ ET (Table 5) and it shows a low performance in simulating the daily evapotranspiration (Table 4) from the stony soils. However in the case non-stony soil, the performances of the AquaCrop model are acceptable and such result is consistent with that obtained from other field surveys carried out in the same environment, in a nonstony soil. It is the case of the daily evapotranspiration of tomato, which has been correctly simulated by AquaCrop (Palumbo et al., 2012; Katerij et al., 2013) if the crop is adequately supplied with irrigation water.

The performance here reported for CRITERIA can be considered as an original result because it takes into account different granulometric conditions of soils, within the Mediterranean area. Moreover, the good aptitude of the model in estimating evapotranspiration at a short time scale, recently reported for tomato (Campi et al., 2014), is here confirmed also for wheat.

\section{Conclusions}

Validation tests of the CRITERIA and AquaCrop models on durum wheat crop in southern Italy highlight a good skill of both models to simulate seasonal evapotranspiration in non-stony soil.

Simulations in stony soils result good only if they are performed by the CRITERIA model. Therefore, CRITERIA can be retained a suitable tool in order to simulate soil water balance, also in the case of stony soils. However further investigations are required for examining the CRITERIA performances in the case of irrigated crops growing in semiarid soils rich in skeleton.

The analysis of the results obtained by AquaCrop shows that the daily values of soil water content are correctly simulated, while in simulating the daily evapotranspiration the model reduces its performance. This result is related to the incorrect simulation of the drainage. Since AquaCrop omits the skeleton in defining soil characteristics, the drainage is underestimates, and as a consequence the water balance results negatively affected. An improvement of the model can be achieved by a more detailed definition of the soil characteristics which cannot neglect the granulometry and the presence of skeleton.

\section{References}

Allen RG, Pereira LS, Raes D, Smith M, 1998. Crop evapotranspiration: guidelines for computing crop water requirements. Irrigation and Drainage paper No. 56. FA0, Rome, Italy.

Baetens JM, Verbist K, Cornelis WM, Gabriels D, Soto G, 2009. On the influence of coarse fragments on soil water retention. Water Resour. Res. 45:W07408.

Belmans C, Wesseling JG, Feddes RA, 1983. Simulation of the water balance of a cropped soil: SWATRE. J. Hydrol. 63:271-86.

Brakensiek and Rawls, 1994. Brakensiek DL, Rawls WJ, 1994. Soil containing rock fragments: effects on infiltration. Catena 23:99-110.

Brisson N, Ruget F, Gate P, Lorgeou J, Nicoullaud B, Tayot X, Plenet D, Jeuffroy MH, Bouthier A, Ripoche D, Mary B, Justes E, 2002. STICS a generic model for simulating crops and their water and nitrogen balances. II. Model validation for wheat and maize. Agronomie 22:69-92.

Brouwer J, Anderson H, 2000. Water holding capacity of ironstone gravel in a typic plinthoxeralf in southeast Australia. Soil Sci. Soc. Am. J. 64:1603-8.
Campi P, Modugno F, Mastrorilli M, Tomei F, Villani G, Marletto V, 2014. Evapotranspiration of tomato simulated with the CRITERIA model. Ital. J. Agron. 2014;9:93-8.

Campi P, Modugno F, Palumbo AD, Mastrorilli M, 2010. Dimensioning the irrigation variables for table grape vineyards in litho-soils. Ital. J. Agron. 4:315-21.

Campi P, Palumbo AD, Mastrorilli M, 2009. Effects of tree windbreak on microclimate and wheat productivity in a Mediterranean environment. Eur. J. Agron. 30:220-7.

Cerda A, 2001. Effects of rock fragment cover on soil infiltration, interrill runoff and erosion. Eur. J. Soil Sci. 52:59-68.

Childs S, Flint AL, 1990. Physical properties of forest soils containing rock fragments. In: G.F. Weetman and R.F. Powers (ed.), Sustained productivity of forest soils. University of British Columbia, Vancouver, BC, USA, pp 95-121.

Coppola A, Dragonetti G, Comegna A, Lamaddalena N, Caushi B, Haikal MA, Basile A, 2013. Measuring and modeling water content in stony soils. Soil Till. Res. 128:9-22.

Coppola A, Gerke HH, Comegna A, Basile A, Comegna V, 2012. Dual-permeability model for flow in shrinking soil with dominant horizontal deformation. Water Resour. Res 48:W0852.

Cousin I, Nicoullaud B, Coutadeur C, 2003. Influence of rock fragments on the water retention and water percolation in a calcareous soil. Catena 53:97-114.

Dann R, Close M, Flinto M, Hector R, Barlow H, Thomas S, Francis G, 2009. Characterization and estimation of hydraulic properties in an alluvial gravel vadose zone. Vadose Zone J. 8:651-63.

Doorenbos J, Kassam AH, 1979. Yield response to water. FAO Irrigation and Drainage Paper No 33. FA0, Rome, Italy.

Fies JC, De Louvigny N, Chanzy A, 2002. The role of stones in soil water retention. Eur. J. Soil Sci. 53:95-104.

Gerke HH, van Genuchten MT, 1993. A dual porosity model for simulating the preferential movement of water and solute in structured porous media. Water Resour. Res. 29:305-19.

Giardini L, 2002. Agronomia generale. Patron Editore, Quarto Inferiore (B0), Italy.

Hanson CT, Blevins RL, 1979. Soil water in coarse fragments. Soil Sci. Soc. Am. J. 43:819-20.

Hendrickx JMH, Khan AS, Bannink MH, Birch D, Kidd C, 1991. Numerical analysis of groundwater recharge through stony soils using limited data. J. Hydrol. 127:173-92.

Heng LK, Hsiao TC, Evett SR, Howell TA, Steduto P, 2009. Testing of FAO AquaCrop model for rainfed and irrigated maize. Agron. J. 101:488-98.

Jamieson PD, Porter JR, Wilson DR, 1991. A test of the computer simulation model ARCWHEAT on wheat crops grown in New Zealand. Fields Crop Res. 27:337-50.

Jarvis NJ, 1994. The MACR0 model (version 3.1) technical description and sample simulations. Reports and dissertations no. 19, Swedish University of Agricultural Sciences, Department Of Soil Sciences, Uppsala, Sweden, p 51.

Katerji N, Campi P, Mastrorilli M, 2013. Productivity, evapotranspiration, and water use efficiency of corn and tomato crops simulated by AquaCrop under contrasting water stress conditions in the Mediterranean region. Agric. Water Manage. 130:14-26.

Marletto V, Ventura V, Fontana G, Tomei F, 2007. Wheat growth simulation and yield prediction with seasonal forecasts and a numerical model. Agric. Forest Meteorol. 147:1-2:71-9.

Marletto V, Zinoni F, 1998. The Criteria project: integration of satellite, radar, and traditional agroclimatic data in a GIS-supported water balance modeling environment. In: EUR 18328, N.R. Dalezios (ed.), Proc. COST 77, 79, 711. Int. Symp. on Applied Agrometeorology and Agroclimatology, 24-26 april 1996, Volos, Grecia.

Mastrorilli M, Katerji N, Rana G, Ben Nouna B, 1998. Daily actual evap- 
otranspiration measured with TDR technique in Mediterranean conditions. Agric. Forest. Meteor. 90:81-9.

Mehuys GR, Stolzy LH, Letey J, Weeks LV, 1975. Effect of stones on the hydraulic conductivity of relatively dry desert soils. Soil Sci. Soc. Am J. 39:37-42.

Modugno F, 2008. Gestione dell'irrigazione del vigneto per uva da tavola coperto con rete antigrandine. Degree Thesis. Università degli Studi di Bari, Italy.

Moriasi DN, Arnold JG, Liew MWV, Bingner RL, Harmel RD, Veith TL, 2007. Model evaluation guidelines for systematic quantification of accuracy in watershed simulations. Trans. ASABE 50:885-900.

Nash JE, Sutcliffe JV, 1970. River flow forecasting through conceptual models part I - A discussion of principles. J. Hydrol. 10:282-90.

Novak V, Knava K, Simunek J, 2011. Determining the influence of stones on hydraulic conductivity of saturated soils using numerical method. Geoderma 161:177-81.

Palumbo AD, Vitale D, Campi P, Mastrorilli M, 2012. Time trend in reference evapotranspiration: analysis of a long series of agrometeorological measurements in Southern Italy. Irrig. Drainage Syst. 25:395-411.

Poesen J, Lavee H, 1994. Rock fragments in top soils: significance and processes. Catena 23:1-28.

Raes D, Steduto P, Hsiao TC, Fereres E, 2009. AquaCrop - The FAO crop model to simulate yield response to water: II. Main Algorithms and Software Description. Agron. J. 101:438-47.

Rana G, Katerji N, 1998. A measurement based sensitivity analysis of
Penman-Monteith actual evapotranspiration model for crops of different height and in contrasting water status. Theor. Appl. Climatol. 60:141-9.

Ravina I, Magier J, 1984. Hydraulic conductivity and water retention of clay soils containing coarse fragments. Soil Sci. Soc. Am. J. 48:736-40.

Ritchie JT, Godwin DC, Otter-Nacke S, 1985. CERES-Wheat: a simulation model of wheat growth and development. Texas A\&M University Press, College Station, TX, USA.

Sharma PP, Carter FS, Halvorson GA, 1993. Water retention by soils containing coal. Soil Sci. Soc. Am. J. 57:311-6.

Steduto P, Raes D, Hsiao TC, Fcreres E, Heng LK, Howell TA, Evett SR, Rojas-Lara BA, Farahani HJ, Izzi G, Oweis TY, Wani SP, Hoogeveen J, Geerts S, 2009. Concepts and applications of AquaCrop: the FAO crop water productivity model. In: W. Cao, J.W. White, E. Wang (eds.), Crop modeling and decision support. Tsinghua University Press, Beijing, China, pp 175-91.

Tokunaga TK, Olson KR, Wan J, 2003. Moisture characteristics of Hanford gravels: bulk, grain-surface, and intragranular components. Vadose Zone J. 2:322-9.

van Dam JC, 2000. Field scale water flow and solute transport. SWAP model concepts, parameter estimation and case studies. PhD Thesis, Wageningen University, Wageningen, the Netherlands.

Vogel T, Gerke HH, Zhang R, van Genuchten MT, 2000. Modeling flow and transport in a two-dimensional dual-permeability system with spatially variable hydraulic properties. J. Hydrol. 238:78-89. 